hollow tube was distinctly visible, the centre being clear like glass, while the outside was wrapped in a smoke-like mist. Even with the naked eye we could distinctly see a spiral motion on the inside of the tube, as if water were either ascending or descending, in which direction it was impossible to tell. Beyond the waterspouts, between the cloud and the sea, a blue sky with sunlit cumulus clouds was plainly seen. These tubes moved at the rate of more than thirty miles an hour, judging from the time ordinarily taken by steamers in crossing the same space. Estimates of the height of the cloud are difficult to make, but at least half the tubes were seen over the promotory of Capo delle Mele, which is about one thousand feet high, and distant about five miles, as the crow flies, from the point of observation.

The phenomenon caused a great panic among the inhabitants, owing to the prediction of Falb that there would be a violent earthquake on that day.

There was subsequently a slight storm of hail and rain; but farther westward, on the coast, the damage done was considerable at San Remo secular olive trees being torn up by the roots and whirled away. No waterspout is, however, known to have burst on the land.

\section{MAURICE HOWARD,}

Alassio, Riviera, Italy, May 26. EUGENE SCHUYLER.

\section{How to make Meteorological Observations at a Distance above the Earth's Surface.}

THE progress of meteorology in the beaten tracks of the usual observations is very satisfactory; but there are several new lines of work, that can be and ought to be carried out, that receive scarcely more than an occasional mention, or a regret that somebody does not do something in the matter. The observation of the conditions of the atmosphere above the earth's surface is perhaps the most important of these questions. I know of no meteorological data so much to be desired as that which is now obtained for short, irregular intervals, by the occasional ascent of a balloon. This, however, is a very expensive and risky method of observation, and has always been looked upon as a novelty rather than a regular method.

The few observations made in balloon-voyages, together with those obtained by means of an occasional captive-balloon ascent, are very valuable, and have been used over and over again in determining constants. The great expense of even a captive balloon, where the observer must go up, has prevented their general introduction into meteorological work.

It has often been proposed to send up self-registering instruments in smaller captive balloons; but, if this has been done, I have not seen accounts of it. The lighter forms (metal thermometer and aneroid barometer) could undoubtedly be used in this way; but the ordinary registering-apparatus is very delicate, and the swaying of the balloon might disturb the adjustments; besides, the original cost of the apparatus is considerable, and, moreover, any damage could not be easily repaired.

In place of a balloon, the kite has been suggested, and E. Douglass Archibald has made some interesting preliminary experiments with this method.

I have seen only the account of his experiments as given in the Meteorologische Zeitschrift for I885 (p. 47); but in this paper there are references to Nature (Nov. 20, 1884) and Quarterly Journal (January, 1883).

Mr. Archibald flies two kites, the one to steady the other. He carried on systematic observations with an anemometer (six inches in diameter) for a year, and finally got results for a height of eleven hundred feet above the ground.

I saw this paper on Mr. Archibald's work a few days ago for the first time; but it interested me very much, as I had been considering the same problem. A year and a half ago I devised a form of apparatus that would seem to promise good results; but it was only some months ago that I suggested the following detailed construction, which is given here for the benefit of any who might wish to carry on any such experiments.

The general form is seen in Fig. I, and consists of a balloon (5) which carries a basket (4) suspended from beneath, and the basket carrying an anemometer (6) with a weight below it.
The balloon is held captive by a three-strand (insulated) wire, which is wound around a reel (2), and passes to a table ( $\mathrm{I}$ ), where the battery and keys are mounted.

The reel (2) must be firmly anchored, and the wires arranged so there will be no danger from electric currents. A cloth ring, with the length of rope (from the balloon) written on it, can be glued to the rope at every hundred feet, so that the observer can see just how much rope is out; and, by means of some instrument for measuring vertical angles, the altitude of the balloon can be measured and the height of the balloon computed.

The apparatus as shown in Fig. 2 might also be sent up in a balloon held captive by an ordinary rope, if a small bichromate-ofpotash battery, with closed hard-rubber cells and a clockwork to break the circuit every five or ten minutes, is also included. The whole apparatus might also be sent up on a kite, if one wished to risk the instruments, which would be destroyed by the sudden falling of the kite.

The method here given allows the observer to control the time of observation, and would seem best on that account. The registering apparatus as shown in Fig. 2 is practically Professor Wild's system, with some important differences, however. I was for a long.

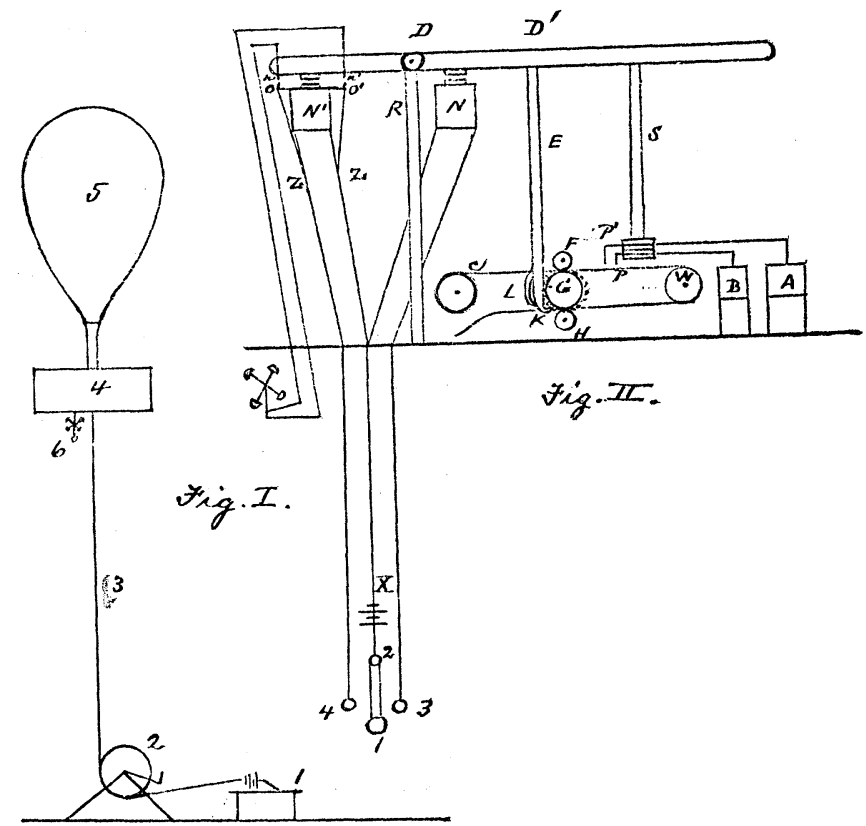

time troubled about the means of moving the registration-paper without clockwork, but Wild's method answers the purpose very well. It must be borne in mind that only a very general description of the apparatus is given here.

The following apparatus is to be placed in the basket suspended from the lower end of the balloon. The basket must be so arranged that the air will have free passage through it when the balloon is ascending or descending. The balloon need only be large enough to carry a few pounds (fifty) to the height of half a mile: it is impossible to foretell just how much the whole apparatus would weigh. A hair hygrometer could also be added to the instruments, but has not been put in the accompanying sketch.

The careening of the balloon would have no effect on the working of the apparatus as shown here, because nothing of the registration arrange ment is free to move except the pointers. In making an apparatus, the best arrangement would be somewhat different from the sketch given here.

The main advantage of this apparatus is the cheapness with which an ordinary aneroid barometer and metal thermometer could be applied to the purpose.

In Fig. $2, R$ is a stand on which the long lever $D$ rests, and turns in the vertical. $\quad N$ and $N^{\prime}$ are two electro-magnets which attract $D$. When the key I joins 2-3, then $N$ acts, and draws $D$ down on the right. When the key I joins 2-4, then $N^{\prime}$ acts, and pushes $D$ up on the right. Self-registering paper is coiled on the wheel $c$, and one end of the paper passes between the rollers $F$ and $G$, and then 
over the roller $W$, and then between the rollers $G$ and $H$. The rollers $F$ and $H$ are the same size; but $G$ is larger, and has a ratchet-wheel at its end. $E$ is a rod joining $D$ at $D^{\prime}$. At the lower end of $E$ is a ratchet-catch $K$, pressed upon by the spring $L$, which is also fastened to $E$. $S$ is a rod fastened to $D$, and has on its lower end a wide framework $=1$

tal slats. Between these slats pass the indicator or pointer of an aneroid barometer $B$, and a metal thermometer $A$. These pointers are made longer than usual, and have attached a needle-point at right angles in the vertical, as shown by $P^{\prime}$ and $P$. This whole apparatus is mounted on a frame or board, and put into a basket suspended from the lower end of a balloon. The three wires below are fine wrapped wire, and serve to hold captive the balloon as well as to cause the self-registrations to be made, by aid of the battery $X$ at the ground. Let the balloon ascend, say roo feet; then put I on 2-3, and $N$ draws $D$ down. This pushes $E$ down (and the ratchet-catch glides over the teeth on $G$ ), and pushes $S$ down also. This last causes $P^{\prime}$ and $P$ to puncture the paper. Now open 2-3 and close 2-4; then $N^{\prime}$ draws $D$ up, $S$ is pulled up, and the points $P^{\prime}$ and $P$ are freed. Also $K$ catches on $G$, and draws off some paper from $c$, the paper being drawn between $F G$, over $W$, and between $G H$. Then the holes pricked by $P^{\prime} P$ are out of the way, and other holes can be punctured at another elevation of roo feet for the balloon. A fixed pencil is also pressed against the paper at each observation, as a reference-point for the puncture by the index-point.

For the hair hygrometer we should have another pointer, $P^{\prime \prime}$. A small anemometer can be suspended from beneath the basket, and kept vertical by means of a weight. This anemometer causes a contact arrangement to close for an instant for every roo feet of wind-motion. The two wires from the anemometer terminate at $n$ and $n^{\prime}$, and, when the magnet $N^{\prime}$ is not attracting the armature, the points $n$ and $n^{\prime}$ are free. When the current is passed through $N^{\prime}$, then $n$ comes in contact with $o$, and $n^{\prime}$ in contact with $o^{\prime} ; o$ and $o^{\prime}$ being joined to the wires 4 and 2 , which run to the reel at the ground. At the ground we insert a telephone or a galvanometer in the wire 4.

The normal condition of the apparatus will be with the current passing through $N^{\prime}$, and the battery $X$ will cause the galvanometer to give a constant reading; but, for every hundred feet of wind, the anemometer will close its circuit for an instant, and the dividing-up of the current at $Z Z$ by including the anemometer in the circuit will cause a momentary deflection of the galvanometer (or will cause a slight sound in the telephone), and the observer can time these with a watch, and get the wind-velocities whenever he wishes them.

In place of $N$ we could insert a spring, and do away with the wire 3 , and probably various other changes would suggest themselves to any one actually constructing the apparatus.

Cincinnati, O., June 27.

FRANK WALDO.

\section{Sea-sickness.}

WITH regard to the subject of sea-sickness, treated of in an article in Science, June 3, I beg to offer a few remarks.

As to the causation of the affection, the process is a gradual one, affecting the balancing sense, which is not interfered with in the case of iron-plate workers. The sickness affecting these workers is caused by the successive shocks due to the hammering, and differs from sea-sickness in character and causation.

An article of mine in the Lancet of June 28, I884, defines seasickness as follows: "The altered sensory impressions affecting those at sea interfere with the co-ordination of movements by which the body is adapted to its surroundings, and with the vomiting and other centres in the medulla oblongata. This interference causes sea-sickness."

The balancing of the body depends on the ordinary sensory impressions, and also on what Foster calls 'the afferent impulses, as it were, of a new sense,' from the semicircular canals, arising from variations of pressure in their ampullæ. With reference to the recent paper of Dr. James, the following quotation from my article above mentioned may be of interest: "In cases where the internal ear has been injured by otorrhœa following scarlatina or measles, we may suppose that the person learns to balance himself without the intervention of this new sense, the absence of which is compensated for in some way; and it is a curious fact, and one which throws considerable light on the etiology of sea-sickness, that such persons invariably escape this disease. . . . That deafness in itself does not prevent sea-sickness is in keeping with the fact that the afferent impulses from the semicircular canals do not give rise to auditory sensations " (vide Foster's 'Physiology,' 2d ed. p. 495).

It is reasonable to believe that no structural change takes place in the semicircular canals, due to the motion of the endolymph, else the longer the motions continued, the more marked would become the sickness. The altered impressions affect the brain directly, and sea-sickness is prevented by their action from being mollified or nullified by the educated conscious ego.

As to drugs, atropine has a sedative action on the medulla, etc., and renders the altered sensory impressions inoperative in producing sea-sickness. It should be given in drop doses of the liquor atropine, B.P., in a teaspoonful of water, every hour, till the physiological effect of the drug is produced.

The bromides have also a sedative action on the brain, but, to prevent sea-sickness, must be given in sufficient doses to produce bromism. As this is a serious condition, and one likely to affect the patient's reason and general health most injuriously, the bromides should be used with great caution, and only when prescribed and their action watched by a medical man.

Steamship ' City of Chicago,' Jersey City, July r.

T. T. REYNOLDS.

\section{The Function of Nitrogen in Manures.}

IN works on agricultural chemistry it is usual to classify manures or plant-food substances as nitrogenous matter, phosphates, and potash; but, while the phosphates and potash enter into the substance of every part of the plant, the amount of nitrogen found in the cereals and food-plants generally is inconsiderable.

A few food-plants contain nitrogen as an essential element of their substance: thus pease contain from two and a half to three and a half per cent, and tea-leaves from five to eight per cent; but in the case of all these plants it is well known that they are capable of drawing the necessary supply of nitrogen from the atmosphere.

Without entering on the question of whether the small traces of nitrogen found in the substance of food-plants generally are essential or accidental, or that other question whether all plants requiring nitrogen are, like animals, capable of deriving it from the air, it is very safe to infer, from the slight trace of nitrogen found in the cereals and food-plants generally, that the ammonia, or nitrogenous substance convertible into ammonia, which is necessary to secure a good crop, has some other and more important function to perform than that of supplying nitrogen to the plant. It may be doubted, even, whether nitrogen is a plant-food for the cereals, or in any way essential to their proper development; but hydrogen, the other element of ammonia, is one of the prime constituents of all vegetable substances, and I infer that it is the easily liberated hydrogen in the ammonia that gives it its manurial value. The function of the nitrogen is simply that of a carrier of hydrogen.

Let me explain. The substance of all trees and plants, wood, stalk, bark, leaves, fruit, etc., is a chemical compound of the three elements, oxygen, hydrogen, carbon. The tree or plant absorbs carbonic acid from the air, which gives it two of the three essential elements, carbon and oxygen. It also takes up water, which is a compound of oxygen and hydrogen, by the roots; and by the mysterious chemistry of organic life, the water and carbonic acid being decomposed on contact, the liberated hydrogen and carbon unite with a portion of the oxygen into definite chemical combinations, the new substance arranging its atoms as cell-contents or cell-walls. All the oxygen of the water, with a portion of that from the carbonic acid, is liberated, and returned to the atmosphere. Given air, water, and potash, and a soil mechanically suitable, and we have all that is necessary to the full and healthy development of timber and fruit trees, flowering plants, and in fact almost every species of vegetation except the grasses, cereals, and principal food- 